constituída por 110 indivíduos com paralisia cerebral. A recolha de dados foi realizada através da consulta do processo clínico do utente existente na instituição, pela observação clínica e pelos dados fornecidos pelos pais/tutores legais ou pelo próprio. O diagnóstico de bruxismo do sono teve por base os critérios de diagnóstico propostos pela Academia Americana de Medicina do Sono, em 2001.

Resultados: A população estudada foi maioritariamente do género masculino (52,7\%), com uma média de idades de $42,9 \sim 13,61$. No geral, 74,5\% dos indivíduos apresentaram bruxismo, sendo $16,4 \%$ bruxismo de vigília e 14,5\% bruxismo do sono. Quando avaliada a relação do bruxismo com o tipo de paralisia cerebral, o tipo espástico foi o mais comum (75\%), não sendo, no entanto, significativo estatisticamente. Não foram verificadas associações significativas do bruxismo com o tipo de localização, com a deficiência intelectual e sensorial, presença de epilepsia, presença de movimentos involuntários e medicação. Por outro lado, quando avaliada a presença de facetas de desgaste e o seu brilho foi verificada uma associação significativa, sendo que, através da regressão logística, constatou-se que o brilho é significativo na previsão do bruxismo.

Conclusões: Com base na elevada prevalência de bruxismo na amostra, verificou-se uma necessidade urgente para a implementação de opções de tratamento para esta patologia em indivíduos com paralisia cerebral. São necessários mais estudos com protocolos de diagnóstico padronizados e amostras representativas para avaliar os fatores que influenciam a presença dos vários tipos de bruxismo.

http://doi.org/10.24873/j.rpemd.2017.12.139

\section{\#117 Cuidados preventivos de saúde oral em Portugal: Resultados do INSEF 2015}

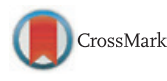

Irina Kislaya*, Paula Braz, Joana Santos, Liliana Antunes, Ana João Santos

Departamento de Epidemiologia, Instituto Nacional de Saúde Dr. Ricardo Jorge, IP

Objetivos: Uma boa saúde oral constitui um factor determinante para a qualidade de vida. As patologias orais, que estão entre as doenças mais prevalentes em Portugal, podem ser prevenidas com correctos comportamentos de higiene oral e consultas regulares. Este estudo tem como objectivo descrever os hábitos de higiene oral na população Portuguesa, avaliar a utilização de cuidados médico-dentários e a sua associação com variáveis sociodemográficas.

Materiais e métodos: Realizou-se um estudo epidemiológico transversal utilizando os dados do $1 .^{\circ}$ Inquérito Nacional de Saúde com Exame Físico (INSEF 2015), numa amostra representativa da população Portuguesa com idade entre os 25 e os 74 anos ( $\mathrm{n}=4911)$. Para identificar factores associados aos comportamentos correctos de higiene oral e a utilização dos cuidados médico-dentários, utilizou-se a regressão de Poisson para estimar as razões de prevalência ajustados (aPR; [IC95\%]) da escovagem regular dos dentes e realização de consultas regulares, de acordo com sexo, idade, nível de escolaridade, rendimento, situação perante o trabalho e região.
Resultados: Do total de participantes, 65\% declararam escovar os dentes pelo menos 2 vezes por dia e $34,2 \%$ visitaram regularmente um profissional de saúde oral. A adesão à escovagem dentária regular foi associada ao sexo feminino (aPR=1,4; $[1,3 ; 1,5])$ e ter ensino secundário (aPR=1,5; $[1,3 ; 1,7])$ ou superior ( $\mathrm{aPR}=1,7 ;[1,5,1,9])$. Contudo, no Norte $(\mathrm{aPR}=0,8$; $[0,7 ; 0,9])$, Centro (aPR=0,7; $[0,6 ; 0.8])$ e Açores (aPR=0,8; $[0,7 ; 0,9])$ observou-se uma menor adesão. A realização de consultas regulares foi associada ao sexo feminino (aPR=1,2; $[1,1 ; 1,4])$, e ter ensino secundário ( $\mathrm{aPR}=1,9 ;[1,5 ; 2,4])$, ou superior $(\mathrm{aPR}=1,9$; $[1,4 ; 2,5])$. Os desempregados $\mathrm{aPR}=0,7 ;[0,5 ; 0,9])$, os indivíduos com baixo rendimento $(\mathrm{aPR}=0,6 ;[0,5 ; 0,7])$ e os residentes no Alentejo (aPR=0,7; $[0,6 ; 0,9])$ foram menos assíduos a visitar um profissional de saúde oral regularmente.

Conclusões: Os resultados evidenciam uma relação entre ser do sexo masculino, ter um menor nível de escolaridade e rendimento, e estar desempregado com a menor adopção de comportamentos preventivos em saúde oral. Estes resultados mostram a necessidade de implementar medidas que promovam a literacia em saúde oral em Portugal e se direccionem para os subgrupos identificados. A menor adesão à prática de escovagem regular e a menor utilização de cuidados médico-dentários em algumas regiões do país carecem de uma investigação adicional que englobe variáveis contextuais.

http://doi.org/10.24873/j.rpemd.2017.12.140

\#118 Alterações das variáveis cefalométricas nos diferentes grupos étnicos- Revisão sistemática

Inês Alexandre Neves Francisco*, Liliane Fernandes, Adriana Guimarães, Margarida Bastos Lopes, Luisa Maló, Francisco Fernandes do Vale

Pós-graduação em Ortodontia da Faculdade de Medicina da Universidade de Coimbra (FMUC)

Objetivos: O diagnóstico e plano de tratamento de pacientes ortodônticos de diferentes etnias requer um padrão cefalométrico diferenciado, tendo em conta as características craniofaciais inerentes à etnia em estudo. O objetivo deste estudo é responder à questão avançada elaborada segundo o modelo PICO: 'Existem diferenças nos valores das normas cefalométricas entre indivíduos de raça caucasiana e raça negra?'

Materiais e métodos: Foi realizada uma pesquisa bibliográfica recorrendo às seguintes bases de dados primárias PubMed/MEDLINE, ScienceDirect e EBSCOhost. Foram utilizadas as seguintes palavras-chave: 'orthodontic'; "cephalometric study"; "population"; "ethnic study" combinadas e associadas com conectores boleanos "AND" e "OR. Os limites da pesquisa estabelecidos foram estudos realizados em humanos, em língua portuguesa ou inglesa e com data de publicação entre março de 2007 e março de 2017. A avaliação qualitativa dos estudos selecionados foi efetuada recorrendo ao preenchimento dos questionários Critical Appraisal Skills Programme.

Resultados: Foram recolhidos 279 estudos. Destes, 19 artigos foram considerados com potencial interesse. Após a leitura integral e a aplicação dos critérios de inclusão e exclusão, 12 foram eliminados. Das 7 publicações aceites, ape- 